\title{
Constrained Control and Optimization of Tubular Solid Oxide Fuel Cells for Extending Cell Lifetime
}

\author{
Benjamin J. Spivey, John D. Hedengren, and Thomas F. Edgar
}

\begin{abstract}
Extending fuel cell lifetime is a necessary objective for reducing fuel cell power generation cost of electricity. Capital costs comprise the most significant fraction of the cost of electricity. Reducing the frequency of fuel cell replacement can be achieved by implementing a control strategy that prevents excursions into operating regions causing failure. In this paper we implement a constrained MIMO model predictive controller (MPC) to avoid the failure modes relevant for a high-temperature tubular solid oxide fuel cell (SOFC) system while performing load-following. The primary causes of failure are catalyst poisoning, fuel or air starvation, carbon deposition, and microcracking. Prior steady-state thermomechanical stress analysis in literature has demonstrated that the minimum cell temperature and maximum negative radial thermal gradient are primary causes of microcracking in the SOFC. State-of-the-art SOFC control literature often seeks to track a mean or outlet cell temperature. The authors have presented the first approach to control the primary two causes of thermally-driven microcracking in tubular SOFCs using constrained control. Constraints are also incorporated into a steady-state optimization to ensure a feasible optimum.
\end{abstract}

\section{INTRODUCTION}

Solid oxide fuel cell systems indicate promise for high efficiency and low emission stationary power generation, particularly for distributed energy applications [1], [2]. Achievable efficiencies range from $50 \%$ in stand-alone applications to $70 \%$ in hybrid gas turbine-solid oxide fuel cell (GT-SOFC) systems. The high effluent temperature of SOFCs makes them suitable for cogeneration, thereby raising the efficiency ceiling to $80-90 \%$ [3]. High operating temperatures from $600-1000^{\circ} \mathrm{C}$ also permit internal or external reformation of hydrocarbon fuels.

Primary challenges that have slowed widespread application of SOFCs for stationary power generation

B. Spivey is with the Department of Chemical Engineering, The University of Texas at Austin, Austin, TX, 78712 ben. spivey@utexas.edu

J. Hedengren is with the Department of Chemical Engineering, Brigham Young University, Provo, UT, 84602 john. hedengren@byu.edu

T. Edgar is with the Department of Chemical Engineering, The University of Texas at Austin, Austin, TX, 78712 edgardche.utexas.edu are premature cell degradation and a limited power operating range due to failure concerns. The Solid State Energy Conversion Alliance has set a lifetime goal of 40,000 h, and recent reports have demonstrated successful $5,000 \mathrm{~h}$ stack tests by Siemens Power Generation. A further test goal of $25,000 \mathrm{~h}$ has been set for 2015 [4]. Primary failure modes are thermally-driven cracking and delamination, corrosion, redox material degradation, and catalyst poisoning. Cell thermal management is especially challenging to control. Several researchers have found that a low local cell temperature is the primary contributor to high thermal stresses followed by high negative radial thermal gradients; the low cell temperature causes high stress based on assuming a zero-stress state at the sintering temperature [13], [14]. The same researchers have cited the need for advanced control to address cell thermal reliability issues.

Extending fuel cell lifetimes via advanced control will reduce the SOFC cost of electricity and lower barriers to power generation applications. The state of the art in SOFC control commonly mitigates failure by choosing the controlled variables (CV) to maintain cell lifetime - steam-to-carbon ratio, local temperatures, and fuel/air utilizations [5]. SOFC controls literature have proposed PID control, optimal control, and various model-based control solutions. Mueller and Junker demonstrated an unconstrained MIMO linear quadratic regulator to control power, lumped cell temperature, combustor temperature, voltage, and gas turbine shaft speed. The fuel cell temperature is tracked by the controller, but the mean temperature demonstrates an upward drift for large step changes [11]. Researchers often seek to minimize thermal stresses by reducing variation of a nominal stack temperature using a lumped fuel cell model or outlet gas temperature [6], [7], [8], [9], [11]. Another indirect approach demonstrated for controlling thermal stresses is minimizing voltage variation using predictive control techniques [10], [12]. A thorough review of SOFC control literature is provided in literature [15].

While much research exists regarding SOFC con- 
trol for load-following and maintaining lifetime goals, the authors have presented the first work that directly controls tubular SOFC thermal stress drivers identified via thermomechanical finite element analysis [15]. This work selects the minimum cell temperature and maximum radial thermal gradient as key controlled variables for extending fuel cell lifetime. Constrained control is implemented to prevent $\mathrm{CV}$ excursions while only setting the power as a tracked CV. The present work demonstrates a successful application of linear MPC to follow sequential load changes while satisfying cell lifetime operability constraints. In addition, constrained optimization is applied to minimize SOFC annual operating cost while ensuring maintenance of lifetime constraints. Satisfaction of these constraints is critical to ensure a feasible optimum.

An overview of the SOFC system model is presented in the following section. Next, the simulation approaches for open-loop dynamics, closed-loop load following, and optimization are discussed. Results demonstrate the capability of linear model-predictive control to follow load setpoints subject to constraints, and an optimal cost is found also within constraints.

\section{MODELING}

The system modeled here is a high-temperature, tubular solid oxide fuel cell system containing three components, the SOFC stack, ejector, and prereformer as shown in Figure 1. As the focus of this

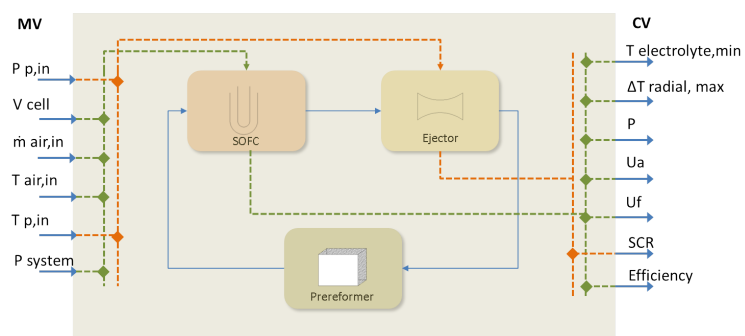

Fig. 1: SOFC system schematic with connections between submodels

work is SOFC lifetime control, the SOFC model is developed in more detail than in the majority of controls literature, and only SOFC system components necessary to ensure use of real manipulated variables (MV) are considered. The system matches the tubular Siemens Power Generation design as modeled by Campanari [16]. A first-principles model has been developed for the three components. The SOFC model is discretized in two dimensions, and the ejector and prereformer are modeled as lumped components. The MV inputs are the cell voltage, air mass flow, system pressure, fuel inlet pressure, and fuel inlet temperature. The air temperature may also be controlled but has little effect on the CVs of interest. The controlled variables are the power output, minimum cell temperature, radial thermal gradient, air utilization, fuel utilization, and steamto-carbon ratio. Further description and validation of the model is provided in [15].

\section{A. Tubular Solid Oxide Fuel Cell}

The solid oxide fuel cell dynamic model is developed to investigate advanced control and optimization strategies that incorporate constraints on the drivers of thermomechanical stress and other modes of failure. Key challenges in modeling the SOFC are addressing the nonlinear, multiscale dynamics; time scales range from electrical transport in milliseconds, chemical transport in tenths of a second, and thermal transport in minutes to hours. Important features of the model are listed as follows:

- The SOFC model is discretized in two dimensions in axial and radial directions.

- Temperature-critical properties are modeled as a function of temperature, such as the nonlinear specific heat and thermal resistance relations.

- Concentric tube radiation occurs between the air supply tube and cathode surface.

- The single cell model represents all cells and exists within the stack center with adiabatic boundaries.

- The air and fuel chambers may contain up to seven chemical species: $\mathrm{H}_{2}, \mathrm{H}_{2} \mathrm{O}, \mathrm{O}_{2}, \mathrm{~N}_{2}$, $\mathrm{CH}_{4}, \mathrm{CO}$, and $\mathrm{CO}_{2}$.

- Current flows in the circumferential direction but not longitudinal due to equipotential voltage.

- The dynamic model time update is a minimum of one second to ensure validity of the electrical and gas transport quasi-steady-state (QSS) assumption.

A cross-section demonstrating the twodimensional model is shown in Figure 2. The fuel cell layers are modeled separately in the radial direction having one volume each and are listed as follows: the supply tube air chamber, supply tube solid, cathode air chamber, cathode solid, electrolyte solid, anode solid, and anode air chamber. Each layer is discretized in the axial direction with ten volumes. The total number of differential and algebraic states per radial segment is sixty-seven.

Key model equations demonstrate the modeling approach used as follows: 


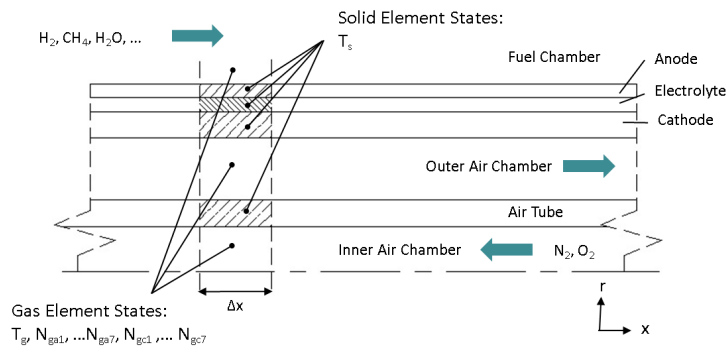

Fig. 2: The SOFC cross-section illustrates the seven finite volumes in the radial direction (not to scale)

\section{Material Balance}

$$
\dot{N}_{i, \text { out }}=\dot{N}_{i, \text { in }}+\sum_{j=1}^{3} v_{i} r_{j}\left[\mathrm{~mol} \mathrm{~s}^{-1}\right] ;
$$

Steam Reformation Reaction Rate

$r_{C H_{4}}=A \exp \left(-\frac{E_{a}}{R T}\right) p_{C H_{4}}\left[m m^{-1} s^{-1}\right] ;$

Water-Gas Shift Reaction Rate

$$
\begin{aligned}
& r_{\text {shift }}=k\left(X_{\mathrm{H}_{2} \mathrm{O}} X_{\mathrm{CO}}-\frac{X_{\mathrm{H}_{2}} X_{\mathrm{CO}_{2}}}{K_{e q}}\right) \\
& {\left[\mathrm{mol} \mathrm{m}^{-3} \mathrm{~s}^{-1}\right] \text {; }}
\end{aligned}
$$

Nernst Equation

$$
\begin{aligned}
V_{o c} & =V_{H_{2}}^{0}+\frac{R T}{2 F} \ln \left(\frac{p_{H 2} p_{O_{2}}^{0.5}}{p_{H_{2}} O}\right) \\
V_{H_{2}}^{0} & =-\frac{\Delta G_{0}}{2 F}+\frac{\Delta S_{0}}{2 F}(T-298) ;
\end{aligned}
$$

Realized Cell Voltage

$$
V_{\text {cell }}=V_{o c}-\eta_{\text {act }}-\eta_{\text {conc }}-\eta_{\text {ohm }} ;
$$

Gas Energy Balance

$\left.\dot{N} M W c_{p} T_{g}\right|_{i, \text { out }}=\left.\dot{N} M W c_{p} T_{g}\right|_{i, \text { in }}+$ $\sum_{j} h_{j} A_{j}\left(T_{s, \text { surf }_{i j}}-T_{g_{i}}\right)-\sum_{k} \Delta H_{i k} r_{i k} ;$

\section{Solid Energy Balance}

$$
\begin{aligned}
\rho V c_{p, i} \frac{d T_{s, i}}{d t}=h A\left(T_{g_{i}}-T_{s, s u r f, i}\right)+ \\
k A \frac{d T_{s, i}}{d x}+k A \frac{d T_{s, i}}{d r}+ \\
\left.\varepsilon F_{i} \sigma A\left(T_{s, \text { opp }}^{4}-T_{s}^{4}\right)\right|_{i}+\dot{Q}_{\text {elec }} .
\end{aligned}
$$

\section{B. Ejector and Prereformer}

The fuel cell ejector operates as a mixer to recycle spent fuel flow with pure feed fuel flow. Early ejector modeling for SOFC had been performed by Marsano [18]. The ejector model used in this work is based upon a model developed by Zhu [17]. The model is unique from refrigeration ejector models as it mixes hot gases and creates a much lower pressure rise than refrigeration applications. A two-dimensional function for secondary flow velocity, as shown in Equation 8 , provides a more accurate model than prior SOFC ejector models:

$$
v(r)= \begin{cases}V_{p, 3} & 0 \leq r \leq R_{p, 3} \\ V_{p, 3}\left(\frac{R_{3}-r}{R_{3}}\right)^{\frac{1}{n_{v}}} & R_{p, 3}<r \leq R_{3}\end{cases}
$$

The prereformer serves to crack higher hydrocarbons than methane and convert a fraction of methane to hydrogen. The reformer is modeled as an adiabatic reactor, and the heat consumed by endothermic reactions is provided by the inlet stream. Further details of the ejector and prereformer models is provided in literature [15].

\section{SIMULATION APPROACH}

\section{A. Open-Loop Dynamics}

Dynamic simulations of the SOFC system model are performed in Simulink. The SOFC is modeled in the APMonitor modeling language interfaced with the APOPT solver. The ejector and prereformer are modeled in MATLAB. The component models are solved sequentially at each time step of one second in Simulink.

The SOFC partial differential equations are discretized spatially in two dimensions and in time, resulting in a differential and algebraic equation (DAE) system. The SOFC is modeled as a DAE system in open equation format within APMonitor which transcribes the DAE to a large-scale nonlinear programming problem (NLP) via orthogonal collocation. The NLP is solved simultaneously with APOPT in the form shown in Equation 9:

$$
\begin{aligned}
0 & =f(\dot{x}, x, u) \\
0 & =g(x, u) \\
x_{\min } & \leq x(k) \leq x_{\max }
\end{aligned}
$$

where $x$ represents the model states, and $u$ represents model inputs. State constraints are added to improve convergence. 


\section{B. Closed-Loop Control}

The SOFC controller consists of two decentralized linear controllers with one MIMO and one SISO controller. The SISO controller operates on air mass flow to maintain air utilization within operability limits, and the MIMO controller operates on the remaining $\mathrm{MVs}$ and CVs. A constrained model predictive controller tracks only the CVs having a desired setpoint. Remaining CVs may be operated freely within operating limits. A Kalman Filter is used to estimate control model states based on CV measurements.

A transfer function control model is identified using the MATLAB System Identification Toolbox, and the transfer function model is converted to a statespace model using an inverse Laplace transform. The linear control model is discretized at a control time step of $10 \mathrm{~s}$ and is shown in Equation 10:

$$
\begin{aligned}
x_{n_{x}}(k+1) & =A_{n_{x}} x_{n_{x}}(k)+B_{n_{x}} u(k) \\
y(k) & =C_{n_{x}} x_{n_{x}}(k) .
\end{aligned}
$$

An augmented state-space model with integration is chosen to eliminate $\mathrm{CV}$ offset.

The MPC is formulated as an NLP optimization problem and solved using fmincon with MATLAB. The objective function is composed of three terms representing tracking error, move suppresion, and slack variable weighting as shown in Equation 11:

$$
\begin{aligned}
\min _{\boldsymbol{u}(\boldsymbol{t})} J=\frac{1}{2}\left(\mathbf{y}-\mathbf{y}_{r e f}\right)^{T} \mathbf{Q}\left(\mathbf{y}-\mathbf{y}_{r e f}\right) \\
+\frac{1}{2} \Delta \mathbf{u}^{T} \mathbf{R} \Delta \mathbf{u}+\frac{1}{2} \boldsymbol{\xi}^{T} \mathbf{V} \boldsymbol{\xi},
\end{aligned}
$$

where $\boldsymbol{y}$ is the vector of CVs at all prediction time steps, $\boldsymbol{y}_{r e f}$ is the reference trajectory, $\Delta \mathbf{u}$ is the change in MV between each control time step, and the slack variables are necessarily defined as $\boldsymbol{\xi} \geq 0$. Upper and lower limits are placed as necessary on the MVs and CVs with the latter having soft constraints as shown in Equation 12:

$$
\begin{aligned}
& \boldsymbol{u}_{\min } \leq \boldsymbol{u}(k) \leq \boldsymbol{u}_{\max } \\
& \Delta u_{\min } \leq u(k)-u(k-1) \leq \Delta u_{\max } . \\
& y_{\min } \leq y(k)+\xi(k) \leq y_{\max }
\end{aligned}
$$

Results by Fischer and Seueme indicate that a uniform temperature of $1173 \mathrm{~K}$ causes a stress of 38 $\mathrm{MPa}$, and a radial temperature gradient of $-5000 \mathrm{~K} / \mathrm{m}$ causes a stress of $11 \mathrm{MPa}$ [13]. In the operating case, temperatures are not uniform, and we have chosen a minimum temperature lower limit of $1000 \mathrm{~K}$ and an upper limit for the absolute value of the gradient to be $3000 \mathrm{~K} / \mathrm{m}$.

\section{Optimization}

Optimization is performed to minimize the SOFC total annual cost while ensuring cell lifetime constraints are satisfied. An economic model for the SOFC is defined as the annual cost for purchasing and operating the SOFC to produce the desired power output as shown in Equation 13 similar to a model by Calise [19]:

$$
C_{t o t}=C_{c a p}+C_{o p}
$$

with the total cost, $C_{t o t}$, capital cost, $C_{c a p}$, and operating cost, $C_{o p}$.

Annual operating cost is defined as the cost of fuel, methane, to operate the SOFC for $8,600 \mathrm{~h}, N_{h}$, as shown in Equation 14:

$$
C_{o p}=c_{f} V_{f} N_{h},
$$

with the specific cost of fuel, $c_{f}\left[\$ / m^{3}\right]$, and volumetric flow rate, $V_{f}\left[\mathrm{~m}^{3} / \mathrm{h}\right]$. The fuel cost is chosen as $0.2 \$ / m^{3}$ consistent with current prices in 2011 .

Annualized capital cost is defined as the sum of financing cost, maintenance cost, and insurance cost as shown in Equation 15:

$$
\begin{gathered}
C_{c a p}=C_{f i n}+C_{m a i}+C_{i n s}, \\
C_{f i n}=\frac{C_{p u r} i(1+i)^{N_{h}}}{(1+i)^{N_{h}}-1}, \\
C_{\text {mai }}=\frac{f_{\text {mai }} C_{\text {pur }}}{N_{h}}, \\
C_{\text {ins }}=\frac{f_{\text {ins }} C_{\text {pur }}}{N_{h}} .
\end{gathered}
$$

The financing cost is calculated based on a ten year payback at a $5 \%$ interest rate, $i$, given the initial purchase cost, $C_{\text {pur }}$. The purchase cost is the sum of the fuel cell, inverter, prereformer, and auxiliary equipment costs shown elsewhere [15]. The optimization performance index is equal to the minimum fuel cost as follows in Equations 19 and 20:

$$
\min _{\boldsymbol{u}(\boldsymbol{t})} J=C_{t o t}
$$

$$
\begin{aligned}
\text { s.t. } g(x, u) & =0 \\
u_{\min } & \leq u(k) \leq u_{\max } \\
y_{\min } & \leq y(k) \leq y_{\max }
\end{aligned}
$$


where $g(x)$ represents the SOFC system model, including the SOFC stack, ejector, and prereformer, and hard constraints limit the decision variables and CVs. The optimization problem is solved using the APMonitor optimization mode with APOPT.

\section{RESULTS AND DISCUSSION}

\section{A. Load-Following MPC}

During load-following the MPC adjusts MV values to follow step-wise changes in the power output setpoint as shown in Figure 3. The controller ensures that CVs have negligible to zero violation of the safe operating limits. During the initial power rise to 280 $\mathrm{kW}$, the minimum cell temperature is held at the lower limit of $1000 \mathrm{~K}$; an increased fuel flow rate decreases cell temperature, particularly at the inlet. The thermal gradient is very sensitive to fuel flow rates, showing a numerator dynamics response. A violation may occur due to soft constraints, but higher weights on slack variables can weight the importance of load-following versus constraint satisfaction for each CV. The steam-to-carbon ratio decreases with a power rise as the fuel flow rate increases.

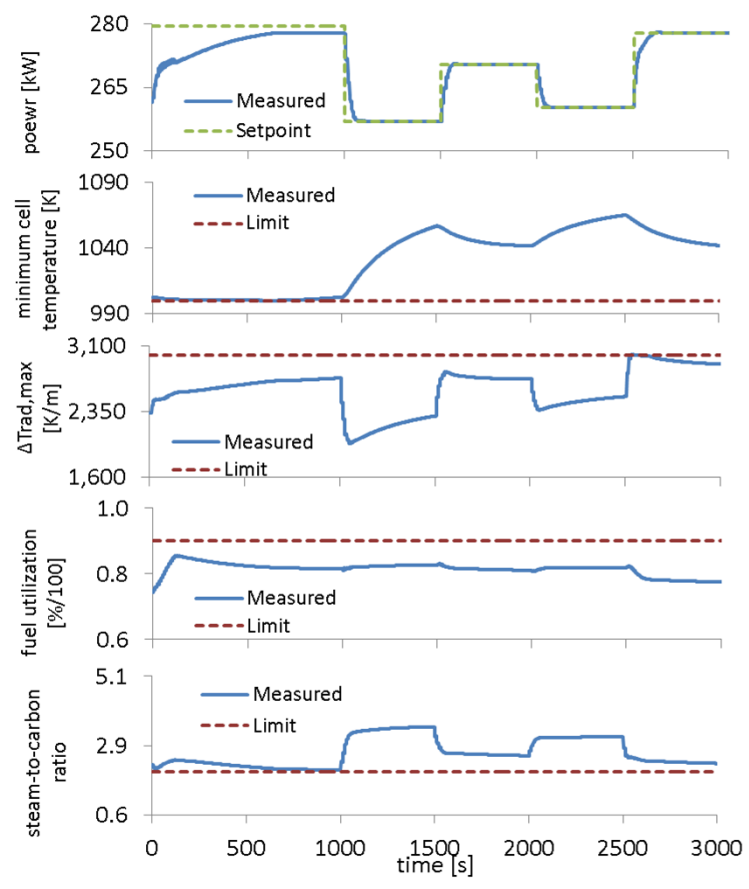

Fig. 3: Constrained predictive control ensures operation remains in a safe region during loadfollowing.

These results are the first to demonstrate sequential load-following with the tubular SOFC while limiting thermal stresses by constraining thermal stress indicators, the minimum cell temperature, and maximum negative radial thermal gradient.

\section{B. Constrained Optimization}

The SOFC design is optimized for a loadfollowing application over a power distribution subject to lifetime constraints. This research considers three unique load distributions represented by load probability density functions (PDF) as shown in Figure 4. Weibull curves represent the distribution of two

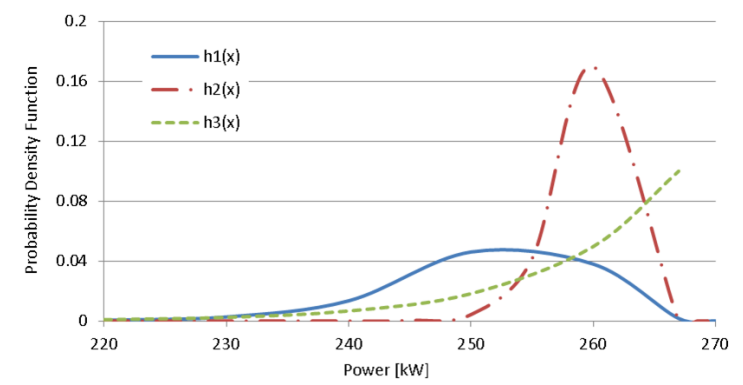

Fig. 4: Probability density curves for three distinct power demand distributions

cases, $h_{1}(x)$ and $h_{2}(x)$; an exponential distribution represents $h_{3}(x)$.

Steady-state optimization found the optimal number of cells for power outputs of 250, 260, and 267 $\mathrm{kW}$ to be $1,681,1,778$, and 1,887 cells, respectively; more cells are needed for higher power outputs for minimal fuel consumption. Total annual cost functions, $f_{i}(x)$ in Figure 5, illustrate costs of operating a fuel cell design at a fixed power output for 8,600 $\mathrm{h}$ in one year. The product of the power demand

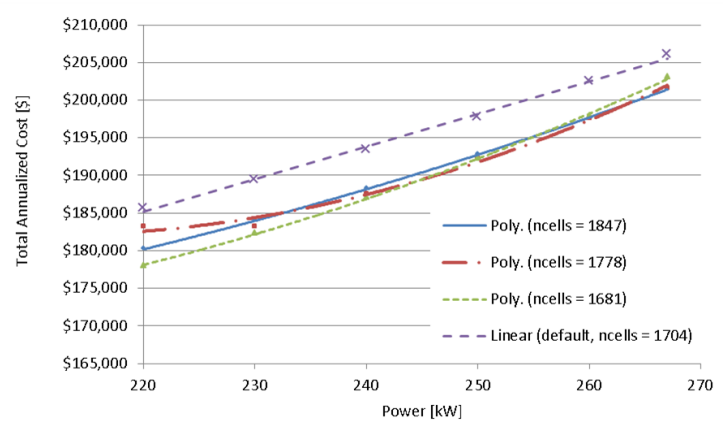

Fig. 5: Total annualized cost of operating an optimal SOFC design at constant power outputs

PDF and total annual cost function is integrated over $\mathrm{x}$ to calculate the expectation value of cost for 
design $i$ with a power demand curve $j$ as shown in Equation 21:

$$
E_{j}\left[f_{i}(x)\right]=\int_{220}^{267} h_{j}(x) \cdot f_{i}(x) d x .
$$

The results for the expected annualized costs for each power demand PDF are shown with respect to the 1,778 cell design in Figure 6. The optimization algo-

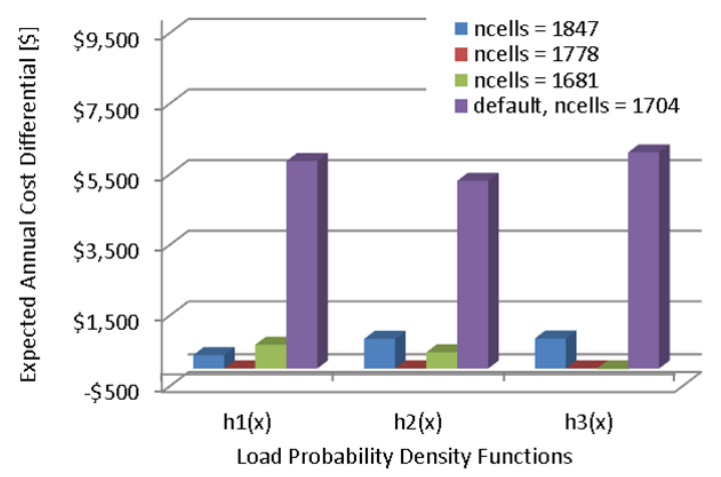

Fig. 6: Difference from minimum cost for each design and load distribution

rithm is successful in producing a 5\% reduction in operating costs while ensuring safe operation within operability constraints using the 1,778 cell case.

\section{CONCLUSIONS}

This research has presented a constrained approach for extending tubular SOFC lifetime while performing dynamic load-following and steady-state optimization. Prior research has determined the key drivers of thermomechanical stress and provided the correlation between the magnitudes of temperature drivers and stress. This work illustrated the dynamic response of the stress drivers during load-following and demonstrated closed-loop constrained control of these stress drivers, ensuring negligible or no violation of operating limits. Constraining the thermal stress drivers reduces the thermal stresses seen in operation thereby extending fuel cell lifetime.

Optimization was performed to find the optimal number of cells and value of steady-state MVs subject to the same operating constraints as the controller. A unique approach is demonstrated for SOFC optimization for load-following applications using PDFs. Optimization resulted in a 5\% reduction of operating costs.

\section{ACKNOWLEDGMENTS}

The authors gratefully acknowledge APMonitor for use of the modeling language and support.

\section{REFERENCES}

[1] J.R. Ferguson, J.M. Fiard, Herbin J. Three-dimensional numerical simulation for various geometries of solid oxide fuel cells. Journal of Power Sources, 58:109-122, 1996.

[2] S. Kurachi, Y. Mizutani, T. Hiroyama, K. Katsurayama, F. Okada, and K. Ukai. Development of a small-scale solid oxide fuel cell (SOFC). In 24th World Gas Conference, Argentina, 2009.

[3] A. Hawkes and M. Leach. Solid oxide fuel cell systems for residential micro-combined heat and power in the UK: Key economic drivers. Journal of Power Sources, 149:72-83, 2005.

[4] J. Pierre. Siemens energy. In 11th Annual SECA Workshop, Pittsburgh, PA, 2010.

[5] M. Bavarian, M. Soroush, I.G. Kevrekidis, and J.B. Benziger Mathematical modeling, steady-state and dynamic behavior, and control of fuel cells: A review. Industrial and Engineering Chemistry Research, 49:7922-7950, 2010.

[6] P. Aguiar, D. Chadwick, and L. Kershenbaum. Modelling of an indirect internal reforming solid oxide fuel cell. Chemical Engineering Science, 57(10):1665-1677, 2002.

[7] C. Stiller, B. Thorud, O. Bolland, R. Kandepu, and L. Imsland. Control strategy for a solid oxide fuel cell and gas turbine hybrid system. Journal of Power Sources, 158:303315, 2006.

[8] R. Kandepu, L. Imsland, B. A. Foss, C. Stiller, B. Thorud, and O. Bolland. Modeling and control of a SOFC-GT-based autonomous power system. Energy, 32(4):406-417, 2007.

[9] F. Mueller, B. Tarroja, J. Maclay, F. Jabbari, J. Brouwer, and S. Samuelsen. Design, simulation and control of a 100 MWclass solid oxide fuel cell gas turbine hybrid system. Journal of Fuel Cell Science and Technology, 7:1-11, 2010.

[10] F. Jurado. Predictive control of solid oxide fuel cells using fuzzy hammerstein models. Journal of Power Sources, 158:245-253, 2006.

[11] F. Mueller, F. Jabbari, J. Brouwer, S.T. Junker, and H. Ghezel-Ayagh. Linear quadratic regulator for a bottoming solid oxide fuel cell gas turbine hybrid system. Journal of Dynamic Systems, Measurement, and Control, 131:1-9, 2009.

[12] H. Huo, X. Zhu, W. Hu, H. Tu, J. Li, and J. Yang. Nonlinear model predictive control of sofc based on a hammerstein model. Journal of Power Sources, 185:338-344, 2008.

[13] K. Fischer and J.R. Seume. Impact of the temperature pro le on thermal stress in a tubular solid oxide fuel cell. Journal of Fuel Cell Science and Technology, 6:1-9, 2009.

[14] A. Nakajo, C. Stiller, G. Harkegard, and O. Bolland. Modeling of thermal stresses and probability of survival of tubular sofc. Journal of Power Sources, 158:287-294, 2006.

[15] B. Spivey. Dynamic Modeling, Model-Based Control, and Optimization of Solid Oxide Fuel Cells. Doctoral dissertation, The University of Texas at Austin, 2011.

[16] S. Campanari. Thermodynamic model and parametric analysis of a tubular sofc module. Journal of Power Sources, 92:26-34, 2001

[17] Y. Zhu, W. Cai, C. Wen, and Y. Li. Fuel ejector design and simulation model for anodic recirculation SOFC system. Journal of Power Sources, 173:437-449, 2007.

[18] F. Marsano, L. Magistri, and A.F. Massardo. Ejector performance influence on a solid oxide fuel cell anodic recirculation system. Journal of Power Sources, 129:216-228, 2004.

[19] F. Calise, M. d'Accadia, L. Vanoli, and M. Spakovsky. Full load synthesis/design optimization of a hybrid SOFC-GT power plant. Energy, 32:446-458, 2007. 